\title{
A Metastable Aluminosilica Compound for Aluminum and Water Transport to the Upper Mantle
}

\author{
Frans J. M. Rietmeijer ${ }^{1}$ and Joseph A. Nuth III ${ }^{2}$ \\ ${ }^{1}$ Department of Earth and Planetary Sciences, University of New Mexico Albuquerque, NM 87131-0001, USA \\ ${ }^{2}$ Astrochemistry Laboratory, Solar System Exploration Division, Code 691, NASA Goddard Space Flight Center, \\ Greenbelt, MD 20771, USA
}

Correspondence should be addressed to Frans J. M. Rietmeijer, fransjmr@unm.edu

Received 17 September 2009; Accepted 5 December 2009

Recommended by Jean-Pierre Burg

It has been suggested that crystalline "phase egg," $\mathrm{AlSiO}_{3} \mathrm{OH}$, with a ratio $\mathrm{Al} / \mathrm{Si}=1$ could carry aluminum and water to the mantle but its natural occurrences are still speculative. An amorphous phase with a fixed and unique, deep metastable eutectic $\mathrm{Al}_{2} \mathrm{Si}_{2} \mathrm{O}_{7}$ composition was produced in laboratory experiments wherein conditions favored kinetically controlled formation of amorphous solids. This experimentally produced kaolinite-dehydroxylate is highly reactive and it is proposed as the precursor of phase egg in subducting slabs of crustal rocks. If so, metastable phases play a role in subduction zones and it then follows that the processes and resulting conditions in these environments can be nonuniform and discontinuous at least at micrometer scales.

Copyright ( 2009 F. J. M. Rietmeijer and J. A. Nuth III. This is an open access article distributed under the Creative Commons Attribution License, which permits unrestricted use, distribution, and reproduction in any medium, provided the original work is properly cited.

\section{Introduction}

The presence of aluminous phases in the upper part of the mantle is still a matter of debate that stands apart from the question of whether such phases are thermodynamically stable or not. It is unlikely that such aluminous phase will exist in the lower mantle at $70-135 \mathrm{GPa}$, that is, between $\sim 1500$ and $2900 \mathrm{~km}[1]$. Aluminous phases were considered as potential carriers of aluminum and water $(\mathrm{OH})$ to the mantle in subduction zones with aluminum hosted in a high-pressure form of $\mathrm{Al}_{2} \mathrm{SiO}_{5}$ [2]. Other experiments concluded that there could be no aluminous phase in the mantle, only $\mathrm{Mg}$ - and Ca-perovskite and magnesiowüstite [3]. Water could be carried in subducting slabs by $\mathrm{OH}-$ bearing minerals such as topaz-OH or "phase egg" [4]. The latter hydrated aluminum silicate potentially forms in rocks of wide-ranging bulk compositions [4], and could be a significant carrier of aluminum and water. Still, natural occurrences of phase egg are speculative [4] although laboratory experiments simulating the subduction of sediments showed that "phase egg" is stable between 1100 and $1300^{\circ} \mathrm{C}$ at $15 \mathrm{GPa}$ [5]. Phase egg, $\mathrm{Al}_{5} \mathrm{Si}_{5} \mathrm{O}_{17}(\mathrm{OH})$, was named after
R. E. Eggleton. Crystalline phase egg was synthesized from $\mathrm{H}_{2} \mathrm{O}$-bearing aluminosilica gels, kaolinite, or pyrophyllite above $1000^{\circ} \mathrm{C}$ at $>10 \mathrm{GPa}$ [6]. These experiments did not reach complete equilibrium but established a unique phase egg $\mathrm{Al} / \mathrm{Si}=1$ atomic ratio that only formed when the starting materials contained substantial amounts of water. Other synthesis experiments at $>11 \mathrm{GPa}$ and $700^{\circ} \mathrm{C}$ on mixtures of cristobalite, $\mathrm{Al}_{2} \mathrm{O}_{3}$, and $\mathrm{Al}(\mathrm{OH})$ refined the "phase egg" crystal structure with an ideal structural formula $\mathrm{AlSiO}_{3} \mathrm{OH}$ with $7.5 \mathrm{wt} \%$ stoichiometric water [7]. However, the strong hydrogen bonding and Al-Si disorder that support high pressure and high temperature stability of phase egg [8] are unrelated to its thermodynamic stability or metastable nature. Phase egg is a metastable mineral stabilized by incorporating $\mathrm{OH}$ at high pressures.

Albeit under much different, highly kinetic conditions an amorphous material with a "peculiar $\mathrm{Al} / \mathrm{Si}$ ratio close to 1" was found in the Haughton impact crater (Canada) that experienced peak impact pressures between 50 and $60 \mathrm{GPa}$ and temperatures of 1400 to $2500^{\circ} \mathrm{C}$ followed by thermal decay to $\sim 1200^{\circ} \mathrm{C}$ in a few milliseconds [9]. This example shows that an anhydrous metastable, amorphous, 
TABle 1: Composition (oxide wt\%) of phase egg (calculated on a water-free basis) obtained in laboratory simulation experiments $[7,8]$, including a sediment analog that contained minor $<1.5 \mathrm{wt} \%$, $\mathrm{TiO}_{2}, \mathrm{FeO}$, trace amounts $(<0.52 \mathrm{wt} \%)$ of $\mathrm{MgO}, \mathrm{CaO}, \mathrm{Na}_{2} \mathrm{O}$, and $\mathrm{K}_{2} \mathrm{O}$, and $6 \mathrm{wt} \% \mathrm{H}_{2} \mathrm{O}$ [5], and the vapor-condensed, amorphous, metastable eutectic aluminosilica compound [10].

\begin{tabular}{lcc}
\hline $\mathrm{Al}_{2} \mathrm{O}_{3}$ & $\mathrm{SiO}_{2}$ & Source \\
\hline \multicolumn{3}{c}{ Phase egg } \\
44.9 & 55.1 & {$[7]$} \\
45.5 & 54.5 & {$[7]$} \\
45.6 & 54.1 & {$[7]$} \\
45.9 & 54.1 & {$[8]$} \\
\hline \multicolumn{3}{c}{ Subducting sediment experiment } \\
44.2 & 55.8 & {$[5]$} \\
46.7 & Metastable aluminosilica compound \\
\hline
\end{tabular}

or crystalline, aluminosilica solid with $\mathrm{Al} / \mathrm{Si}=1$ can exist in nature due to kinetically controlled processes.

In this paper we present an amorphous, metastable aluminosilica compound with the unique $\mathrm{Al} / \mathrm{Si}$ ratio of phase egg (Table 1) that does in fact arise systematically under nonequilibrium conditions that, in our case, were simulated by condensation of $\mathrm{Al}-\mathrm{SiO}-\mathrm{H}_{2}-\mathrm{O}_{2}$ vapors $[10,11]$. Once formed, its metastable nature will readily facilitate hydration to "phase egg."

\section{Laboratory Experiments and Sample Analyses}

Gram quantities of porous aggregate samples, called smokes were produced in Condensation Flow Apparatus that was specifically designed to capture condensation process in its earliest stages of solid condensate formation. Details of this apparatus and the experimental conditions to produce the condensate samples are provided in $[12,13]$. Grain formation is a stochastic process that occurred far from chemical equilibrium. The condensed aggregates often consist of hundreds or even thousands of individual amorphous grains of two mixed metal-oxide compositions, namely, aluminosilica (AlSiO) grains. Each grain is connected to only two or three neighboring grains. The condensate grain sizes range from $\sim 2 \mathrm{~nm}$ up to $\sim 100 \mathrm{~nm}$ in diameter. Individual grains in the ultra-thin sections $(\sim 70 \mathrm{~nm})$ of the samples were characterized using a JEOL 2000FX Analytical Transmission Electron Microscope (ATEM) that was operated at an accelerating voltage of $200 \mathrm{keV}$ and was equipped with a Tracor-Northern TN-5500 energydispersive spectrometer (EDS) for in situ analyses. The standard Cliff-Lorimer thin film procedure was for EDS data reduction [14] using calibrated $k$-factors. Details of the otherwise standard ATEM procedures are provided in $[9$, 10]. Standard selected area electron diffraction was used to determine the crystallographic properties, that is, crystalline (mineral) or amorphous. The typically diffuse ring patterns

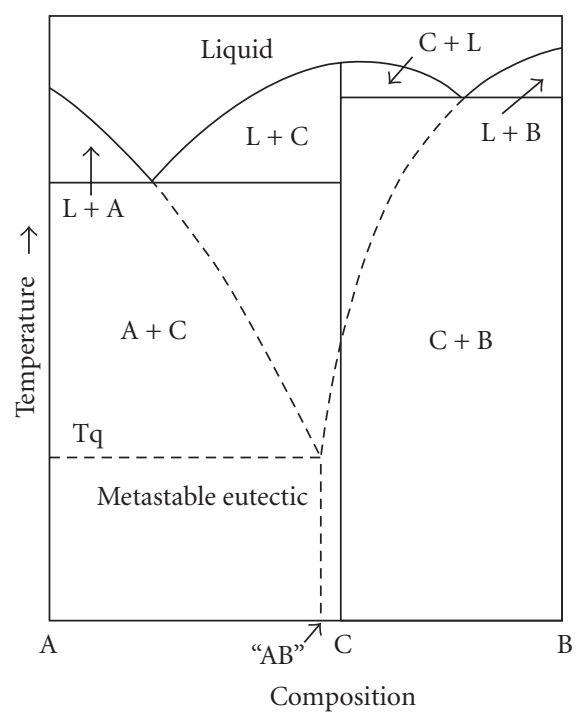

FIgURE 1: The hypothetical binary equilibrium phase diagram A-B showing the position of a (deep) metastable eutectic with a composition "AB" defined at the intersect of the metastable extensions of the liquidus surface (dashed lines) and located in between the compositions of both (stable) eutectic points on the liquidus surface at the top of the diagram (solid lines). This figure was modified after [18].

without diffraction maxima indicated that these condensed aluminosilica grains were amorphous solids.

\section{Amorphous Aluminosilica Compounds}

The aluminosilica grains between $\sim 2 \mathrm{~nm}$ and $\sim 25 \mathrm{~nm}$ that formed during condensation of Al-SiO- $\mathrm{H}_{2}-\mathrm{O}_{2}$ and Fe-Al$\mathrm{SiO}-\mathrm{H}_{2}-\mathrm{O}_{2}$ vapors had compositions that do not match any stoichiometric mineral composition. The mean $\mathrm{Al}_{2} \mathrm{O}_{3}$ (wt $\%$ ) contents of these amorphous grains present two Gaussian distributions, namely, (1) $11.5 \pm 3$ (range: 6-16) and (2) $46.7 \pm 10.8$ (range: $22-71$ ) [10]. The second aluminosilica composition is between the two eutectic compositions in the $\mathrm{Al}_{2} \mathrm{O}_{3}-\mathrm{SiO}_{2}$ phase diagram at $\sim 10 \mathrm{wt} \% \mathrm{Al}_{2} \mathrm{O}_{3}$ and $\sim 80 \mathrm{wt} \%$ $\mathrm{Al}_{2} \mathrm{O}_{3}$ [15]. It is a common and reproducible feature in the nonequilibrium vapor phase condensation experiments $[12,13,16,17]$.

The unique deep metastable eutectic (DME) compositions are constrained by the presence of stable eutectics (Figure 1). This hypothetical phase diagram A-B has two eutectics. When the equilibrium phase boundaries (solid lines) are extended towards lower temperatures (dashed lines) they will intersect at the intermediate composition "AB." $\mathrm{AB}$ is the composition of a DME compound. Its composition is the mean of the measured smallest grain compositions. The quench temperature $(\mathrm{Tq})$ of the condensation experiment is used to plot its position in the diagram, which is typically well below the glass transition temperature. Being a metastable feature it cannot have a fixed temperature in an equilibrium phase diagram. Its composition is the main feature of invariably amorphous DME compounds. 
The compositions of DME solids are insensitive to the $\mathrm{SiO}_{2} / \mathrm{Al}_{2} \mathrm{O}_{3}$ ratio of the condensing vapor.

The mean composition, $46.7 \pm 10.8 \mathrm{wt} \% \mathrm{Al}_{2} \mathrm{O}_{3}$ (Table 1), identifies this phase as a DME kaolinite-dehydroxylate $\left(\mathrm{Al}_{2} \mathrm{Si}_{2} \mathrm{O}_{7}\right)$. This unique aluminosilica composition coincides with the crest of the metastable immiscibility gap and spinodal in the $\mathrm{Al}_{2} \mathrm{O}_{3}-\mathrm{SiO}_{2}$ phase diagram [19]. They separate silica-rich, glass forming from alumina-rich, poor glass-forming compositions [20]. This particular thermodynamic configuration presents ample opportunities to yield a metastable $\mathrm{Al}_{2} \mathrm{Si}_{2} \mathrm{O}_{7}$ compound that can be precursor for metastable "phase egg."

The condensed DME dehydroxylate grains formed during chaotic cycles when the vapor condensation rates exceeded condensate evaporation rates prior to equilibrium condensation when the gas and grains temperatures had equalized [21]. The solids surviving from the preequilibrium regime are dissipative structures that are defined [22] as states of organization of matter where disequilibrium has become a source of order. The prerequisite conditions to form such dissipative structures are (1) supercooling into the solid phase field from high-temperatures in the vapor or liquid phase fields, and (2) at least two stable eutectic points in the phase diagram. When, as many Earth Scientists believe, metastable phases cannot play any role as a natural mineral of the mantle or of subduction zones [23] the key word is "mineral." There is no a priory and obvious reason that metastable compounds could not exist in these environments as a result of kinetic inhibition. An example of natural metastable equilibrium would be sillimanite in aluminosilicate mineral assemblages in highgrade to ultrahigh-grade, aluminous metamorphic rocks [24]. It is too soon to dismiss the possibility of metastable equilibrium and thus the presence of naturally occurring "metastable minerals" and compounds.

\section{Discussion}

The deep metastable eutectic kaolinite dehydroxylate, $\mathrm{Al}_{2} \mathrm{Si}_{2} \mathrm{O}_{7}$, is an amorphous compound with a unique $\mathrm{Al} / \mathrm{Si}$ ratio of unity. Like this anhydrous dehydroxylate, a "phase egg" precursor will be insensitive to the bulk composition of its environment. Metastable "phase egg" would form by high-pressure stabilization [8] during hydration of the amorphous $\mathrm{Al}_{2} \mathrm{Si}_{2} \mathrm{O}_{7}$ compound in a reaction

$$
\mathrm{Al}_{2} \mathrm{Si}_{2} \mathrm{O}_{7}+\mathrm{H}_{2} \mathrm{O}=2 \mathrm{AlSiO}_{3} \mathrm{OH} .
$$

Water for this reaction is probably not a limiting factor in subducting slabs of continental rocks.

We do not know the nature or the extent of small-scale physicochemical processes that may exist in a descending slab or their continuity. At temperatures $>1000^{\circ} \mathrm{C}$, we can only guess what conditions could cause the rapid supercooling required to form the highly metastable kaolinite dehydroxylate compound. Perhaps earthquakes are a triggering mechanism to create small-scale conditions of supercooling. The other question is how the necessary chemical conditions for a metastable phase egg precursor could be achieved.
We suggest two potential pathways, namely, (1) petrological phase changes due to changing pressures and temperatures in subducting sediments [5] and (2) decomposition of cordierite that is being carried downward [25]. In this context, it is noteworthy that laboratory experiments to determine cordierite stability were plagued by metastable equilibrium [26-28] and its thermodynamic stability is still not fully resolved. An amorphous metastable $\mathrm{Al}_{2} \mathrm{Si}_{2} \mathrm{O}_{7}$ compound that is the phase egg precursor could form by decomposition of metastable cordierite in a reaction

$$
\mathrm{Mg}_{2} \mathrm{Al}_{4} \mathrm{Si}_{5} \mathrm{O}_{18} \longrightarrow 2 \mathrm{Al}_{2} \mathrm{Si}_{2} \mathrm{O}_{7}+\mathrm{Mg}_{2} \mathrm{SiO}_{4}
$$

As the water content of cordierite decreases with depth and pressure [29], water required in (1) was freed during this reaction (2).

\section{Conclusions}

Natural occurrences of phase egg to transport water and aluminum to the mantle are speculative and its role is uncertain. Equally uncertain is the notion that metastable minerals and compounds could exist in subducting slabs. Phase egg's atomic ratio $\mathrm{Al} / \mathrm{Si}=1$ is unique. Accepting that a kaolinite phyllosilicate could not exist in descending slabs, the experimentally verified existence of an amorphous, deep metastable eutectic, kaolinite-dehydroxylate compound offers a possibility that phase egg might exist naturally as a metastable mineral. Once formed in the slabs of crustal rocks, this $\mathrm{Al}_{2} \mathrm{Si}_{2} \mathrm{O}_{7}$ compound becomes a precursor of a natural metastable "phase egg" mineral, $\mathrm{AlSiO}_{3} \mathrm{OH}$. A major unknown at this time is whether transient microenvironments can be created in these slabs that provide the requisite thermodynamic conditions to form the $\mathrm{Al}_{2} \mathrm{Si}_{2} \mathrm{O}_{7}$ aluminosilica precursor.

\section{Acknowledgments}

The authors very much appreciated a constructive review. Frans J. M. Rietmeijer was supported by a grant from the NASA Cosmochemistry Program (NNX07AI39G0). Joseph A. Nuth III is grateful for the support received from the Cosmochemistry Program at NASA Headquarters. The samples were made at the NASA Goddard Space Flight Center. The analyses were conducted in the Electron Microbeam Analyses Facility housed in the Department of Earth and Planetary Sciences at UNM.

\section{References}

[1] S. E. Kesson, J. D. Fitz Gerald, and J. M. Shelley, "Mineralogy and dynamics of a pyrolite lower mantle," Nature, vol. 393, no. 6682, pp. 252-255, 1998.

[2] I. Ahmed-Zaiid and M. Madon, "A high-pressure form of $\mathrm{Al}_{2} \mathrm{SiO}_{5}$ as a possible host of aluminium in the lower mantle," Nature, vol. 353, no. 6343, pp. 426-428, 1991.

[3] T. Irifune, "Absence of an aluminous phase in the upper part of the Earth's lower mantle," Nature, vol. 370, no. 6485, pp. 131-133, 1994. 
[4] M. W. Schmidt, "Lawsonite: upper pressure stability and formation of higher density hydrous phases," The American Mineralogist, vol. 80, no. 11-12, pp. 1286-1292, 1995.

[5] S. Ono, "Stability limits of hydrous minerals in sediment and mid-ocean ridge basalt compositions: implications for water transport in subduction zones," Journal of Geophysical Research B, vol. 103, no. 8, pp. 18253-18267, 1998.

[6] R. A. Eggleton, J. N. Boland, and A. E. Ringwood, "High pressure synthesis of a new aluminium silicate: $\mathrm{Al}_{5} \mathrm{Si}_{5} \mathrm{O}_{17}(\mathrm{OH})$," Geochemical Journal, vol. 12, pp. 191-194, 1978.

[7] M. W. Schmidt, L. W. Finger, R. J. Angel, and R. E. Dinnebier, "Synthesis, crystal structure, and phase relations of $\mathrm{AlSiO}_{3} \mathrm{OH}$, a high-pressure hydrous phase," The American Mineralogist, vol. 83, no. 7-8, pp. 881-888, 1998.

[8] X. Xue, M. Kanzaki, H. Fukui, E. Ito, and T. Hashimoto, "Cation order and hydrogen bonding of high-pressure phases in the $\mathrm{Al}_{2} \mathrm{O}_{3}-\mathrm{SiO}_{2}-\mathrm{H}_{2} \mathrm{O}$ systemml: an NMR and Raman study," The American Mineralogist, vol. 91, no. 5-6, pp. 850-861, 2006.

[9] I. Martinez, U. Schärer, and F. Guyot, "Impact-induced phase transformations at 50-60 GPa in continental crust: an EPMA and ATEM study," Earth and Planetary Science Letters, vol. 119, no. 1-2, pp. 207-223, 1993.

[10] F. J. M. Rietmeijer and J. M. Karner, "Metastable eutectic gas to solid condensation in the $\mathrm{Al}_{2} \mathrm{O}_{3}-\mathrm{SiO}_{2}$ system," Journal of Chemical Physics, vol. 110, no. 9, pp. 4554-4558, 1999.

[11] F. J. M. Rietmeijer, J. A. Nuth III, P. Rochette, J. Marfaing, A. Pun, and J. M. Karner, "Deep metastable eutectic condensation in $\mathrm{Al}-\mathrm{Fe}-\mathrm{SiO}-\mathrm{H}_{2}-\mathrm{O}_{2}$ vapors: implications for natural $\mathrm{Fe}-$ aluminosilicates," The American Mineralogist, vol. 91, no. 10, pp. 1688-1698, 2006.

[12] J. A. Nuth III, S. L. Hallenbeck, and F. J. M. Rietmeijer, "Laboratory studies of silicate smokes: analog studies of circumstellar materials," Journal of Geophysical Research, vol. 105, no. A5, pp. 10387-10396, 2000.

[13] J. A. Nuth III, F. J. M. Rietmeijer, and H. G. M. Hill, "Condensation processes in astrophysical environments: the composition and structure of cometary grains," Meteoritics \& Planetary Science, vol. 37, no. 11, pp. 1579-1590, 2002.

[14] G. Cliff and G. W. Lorimer, "The quantitative analysis of thin specimens," Journal of Microscopy, vol. 103, no. 2, pp. 203-207, 1975.

[15] S. Aramaki and R. Roy, "Revised equilibrium diagram for the system $\mathrm{Al}_{2} \mathrm{O}_{3}-\mathrm{SiO}_{2}$," Journal of the American Ceramic Society, vol. 45, no. 5, pp. 229-242, 1962.

[16] F. J. M. Rietmeijer, A. Pun, Y. Kimura, and J. A. Nuth III, "A refractory $\mathrm{Ca}-\mathrm{SiO}-\mathrm{H}_{2}-\mathrm{O}_{2}$ vapor condensation experiment with implications for calciosilica dust transforming to silicate and carbonate minerals," Icarus, vol. 195, no. 1, pp. 493-503, 2008.

[17] F. J. M. Rietmeijer, A. Pun, and J. A. Nuth III, "A deep metastable eutectic iron-aluminate," Chemical Physics Letters, vol. 458, no. 4-6, pp. 355-358, 2008.

[18] F. J. M. Rietmeijer and J. A. Nuth III, "Metastable eutectic equilibrium brought down to Earth," EOS Transactions of the American Geophysical Union, vol. 81, no. 36, pp. 409, 414-415, 2000.

[19] I. A. Aksay and J. A. Pask, "Stable and metastable phase equilibria and reactions in the $\mathrm{SiO}_{2}-\mathrm{Al}_{2} \mathrm{O}_{3}$ system," Journal of the American Ceramic Society, vol. 58, pp. 507-512, 1975.

[20] J. F. MacDowell and G. H. Beall, "Immiscibility and crystallization in $\mathrm{Al}_{2} \mathrm{O}_{3}-\mathrm{SiO}_{2}$ glasses," Journal of the American Ceramic Society, vol. 52, pp. 17-25, 1969.
[21] B. R. De, "Disequilibrium condensation environments in space: a frontier in thermodynamics," Astrophysics and Space Science, vol. 65, no. 1, pp. 191-198, 1979.

[22] I. Prigogine, "Irreversibility and randomness," Astrophysics and Space Science, vol. 65, no. 2, pp. 371-381, 1979.

[23] B. Wunder and W. Schreyer, "Metastability of the 10- $\AA$ phase in the system $\mathrm{MgO}-\mathrm{SiO}_{2}-\mathrm{H}_{2} \mathrm{O}(\mathrm{MSH})$. What about hydrous MSH phases in subduction zones?" Journal of Petrology, vol. 33, no. 4, pp. 877-889, 1992.

[24] D. E. Harlov, R. Milke, and M. Gottschalk, "Metastability of sillimanite relative to corundum and quartz in the kyanite stability field: competition between stable and metastable reactions," The American Mineralogist, vol. 93, no. 4, pp. 608617, 2008.

[25] M. P. Searle and J. Cox, "Subduction zone metamorphism during formation and emplacement of the Semail ophiolite in the Oman Mountains," Geological Magazine, vol. 139, no. 3, pp. 241-255, 2002.

[26] W. Schreyer and J. F. Schairer, "Compositions and structural states of anhydrous $\mathrm{Mg}$-cordierite: a re-investigation of the central part of the system $\mathrm{MgO}-\mathrm{Al}_{2} \mathrm{O}_{3}-\mathrm{SiO}_{2}$," Journal of Petrology, vol. 2, pp. 324-406, 1961.

[27] W. Schreyer and J. F. Schairer, "Metastable solid solution with quartz-type-structures on the join $\mathrm{SiO}_{2}-\mathrm{MgAl}_{2} \mathrm{O}_{4}$," Zeitschrift für Kristallographie, vol. 116, pp. 60-81, 1961.

[28] W. Schreyer and J. F. Schairer, "Metastable osumilite and petalite-type phases in the system $\mathrm{MgO}-\mathrm{Al}_{2} \mathrm{O}_{3}-\mathrm{SiO}_{2}$," The American Mineralogist, vol. 47, pp. 90-104, 1962.

[29] W. Johannes and W. Schreyer, "Experimental introduction of $\mathrm{CO}_{2}$ and $\mathrm{H}_{2} \mathrm{O}$ into Mg-cordierite," American Journal of Science, vol. 281, pp. 299-317, 1981. 

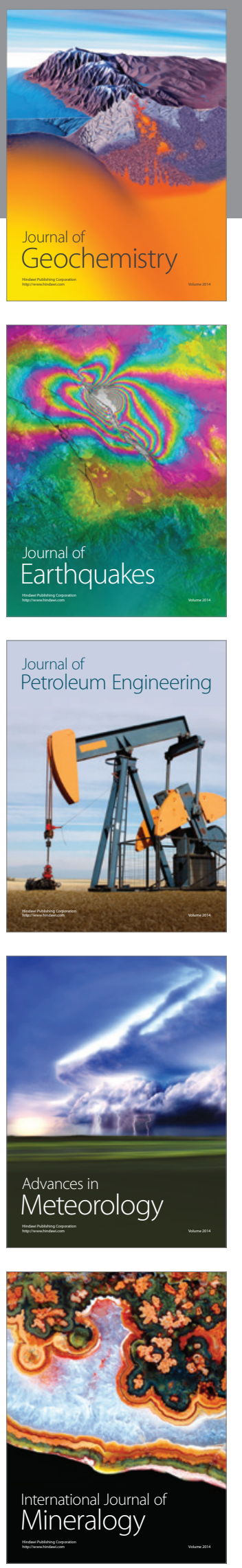
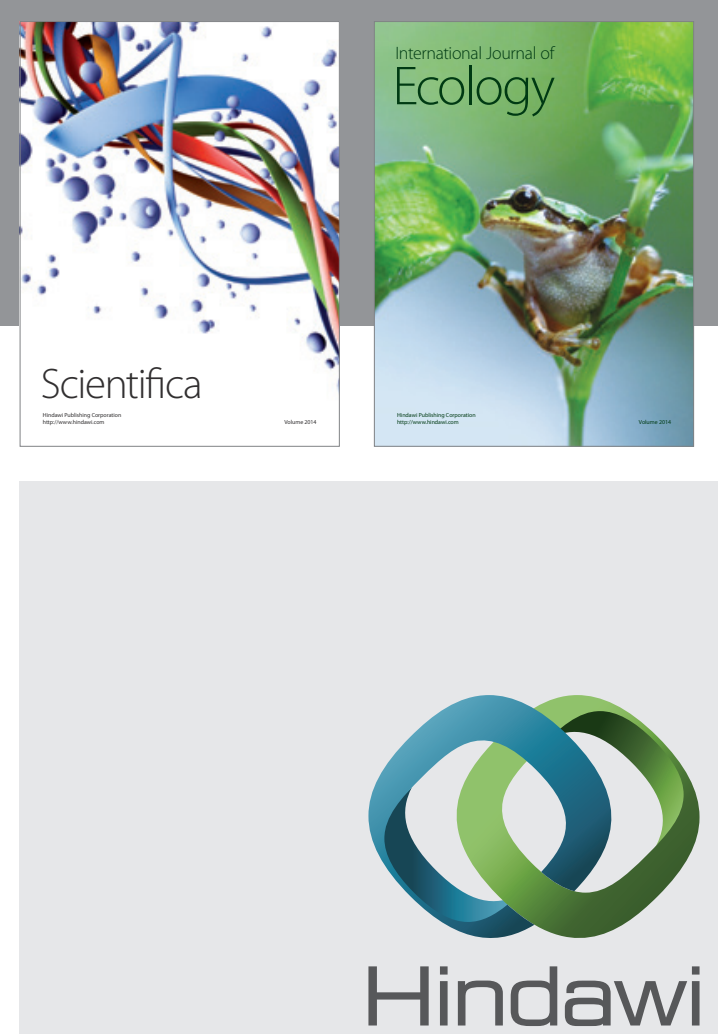

Submit your manuscripts at http://www.hindawi.com
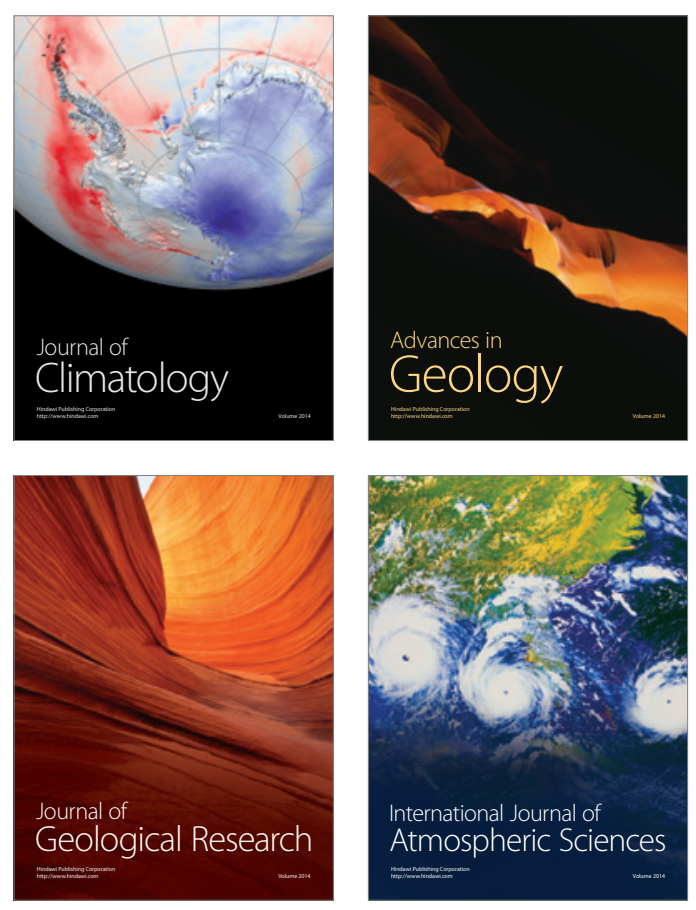
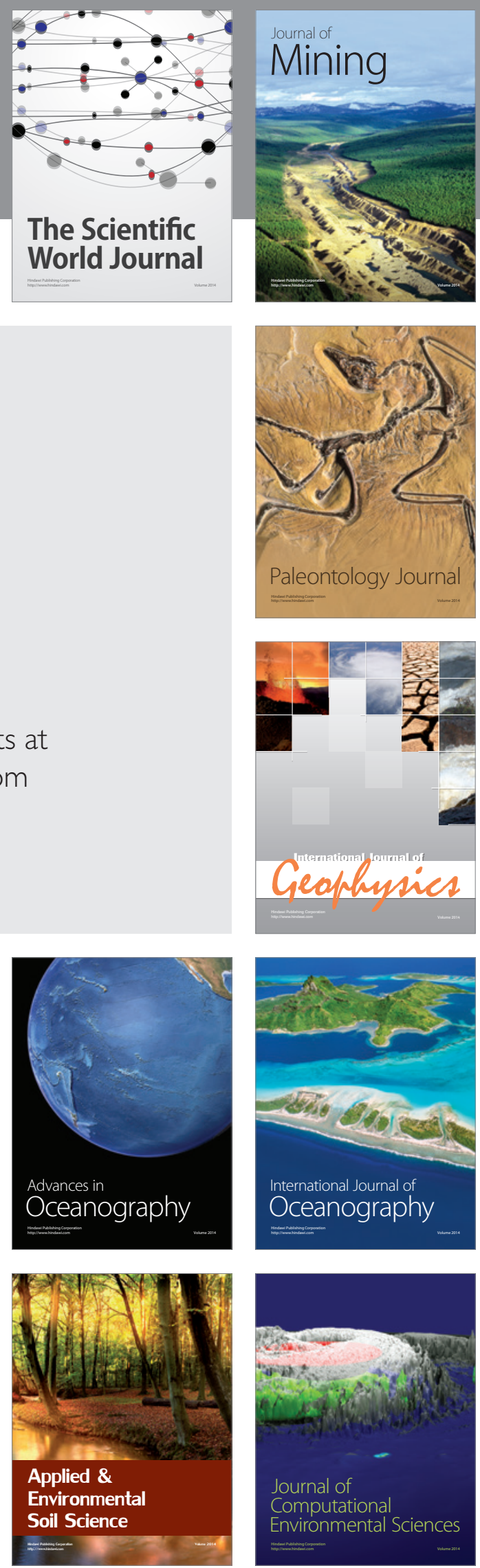